\title{
Recommendations for implementing work-integrated learning in South African schools of pharmacy
}

\author{
Irma Kotzé ${ }^{(1)}$, Gerda Reitsma ${ }^{2}$ (D), René Botha ${ }^{3}$ (D) \\ 1 Division Health Sciences Education, Faculty of Health Sciences, University of the Free State, Bloemfontein, South Africa \\ ${ }^{2}$ Centre for Health Professions Education, Faculty of Health Sciences, North-West University, South Africa \\ ${ }^{3}$ Community-Based Education and Rural Health, Faculty of Health Sciences, University of the Free State, Bloemfontein, South Africa
}

\section{Keywords}

Pharmacy

Recommendations

Work-integrated learning

\section{Correspondence}

Irma Kotzé

Division Health Sciences Education

Faculty of Health Sciences

University of the Free State

Bloemfontein, South Africa

Irma.Kotze@nwu.ac.za

\begin{abstract}
Aim: Pharmacy schools in South Africa need to prove compliance with work-integrated learning (WIL) as articulated in the Good Pharmacy Education Standards (GPES). This study aims to determine the current status of WIL in South African schools of pharmacy. Method: Semi-structured interviews were conducted with heads of pharmacy schools regarding the challenges experienced with the implementation of WIL. Results: Four of the possible nine heads of South African schools of pharmacy participated in the study. Categories and subcategories were identified under the theme 'challenges of WIL'. Conclusion: Findings showed that pharmacy schools in South Africa comply partially with WIL requirements. Possible reasons for partial compliance are challenges experienced relating to resources, campus-based infrastructure and service providers. Based on this study's findings, the authors present several recommendations for the implementation of WIL in South African pharmacy schools.
\end{abstract}

\section{Introduction}

South African higher education is under increased pressure to generate work-ready graduates. According to Thorne (2010), the role of higher education is not only to prepare students for work but also to give them the tools with which to reflect on and learn from experience. According to Jackson (2013): 'workintegrated learning (WIL) is used in undergraduate degrees as an instrument to enhance professional practice and to develop work-ready graduates to a standard that industry expects of them'. WIL is the term given to an activity or programme that: 'integrates academic learning with its application in the workplace' (Edwards et al., 2015). The practice may be real or simulated and can occur in the workplace, at the university, online, face-to-face or any combination of these (Edwards et al., 2015). Patrick and colleagues (2008) indicated that WIL is used as an umbrella term for: 'a range of approaches and strategies that integrate theory with the practice of work in a purposefully designed curriculum'. Calway and Murphy (2007) also define WIL as: 'an attempt by educators to provide a schooling-to-work pathway to support graduate employability'. Campbell and Zegwaard (2012) emphasise that: 'the definition of WIL must be inclusive, involving, for example, practical experiences undertaken by learners as part of their internships and academic courses as well as simulations, real-life case investigations and classroom projects'.

Before 2017, the South African Pharmacy Council (SAPC) had no work-integrated learning (WIL) criteria for the mix of practice sites, supervision, service provider contracts and site requirements, or for the structuring of WIL (South Africa, 1994), especially workplace learning (WPL) where the university and industry need to collaborate. Despite this lack of criteria, many pharmacy schools have been involved with WPL over recent years. 
In the revised 2017 Good Pharmacy Education Standards (GPES) (SAPC, 2017), the SAPC states that all schools of pharmacy must comply with the minimum standards for WIL. The purpose of GPES is to ensure quality pharmacy education in South Africa and to equip students with the necessary competencies to undertake their roles and responsibilities in professional practice. The GPES (SAPC, 2017) states that WIL professional practice experience for pharmacy students must be structured, supervised and extend over a minimum of 400 hours. Pharmacy students must be exposed to an adequate mix of practice facilities such as community pharmacies, hospital pharmacies, primary health care clinics in the private and public sectors, wholesale and manufacturing industries, and regulatory affairs. Written agreements with service providers must be in place, and professional practice sites must comply with the following criteria:

'Meet and exceed all legal and professional standards required to provide patient care; have a patient population that exhibits diversity in culture, medical conditions, gender and age; have an adequate patient population based on the learning objectives for the rotation; provide access to learning and information resources; have a commitment to the education of pharmacy students; have management that supports professional staff involvement in the education of pharmacy students; provide a practice environment that nurtures and supports pharmacist and student interactions with patients; provide regular contact with supervisor to ensure that students receive feedback and have opportunities to ask questions; be adequately equipped with the technology needed to support student training and reflect contemporary practice; provide medication therapy management and patient care services for diverse populations; have adequate professional staff and supportive technical and clerical staff to meet the learning objectives and to provide for optimum time for supervisor and student interaction; and demonstrate a commitment to health promotion and illness prevention'.

Due to the involvement of students, industry partners and higher education institutions (HEls), various challenges are experienced by the triad partnership in implementing WIL. A recurring challenge identified in the literature is the resource intensity of providing WIL (McLennan \& Keating 2008; Patrick et al., 2008).

Some WIL programmes incur extra expenses for students, including travel and transport costs and purchasing practical workplace clothes (Bates, 2005; Davies \& Shirley, 2007). Pitout (2009) and Dwesini (2017) add that finding accommodation is problematic for students, especially where areas of work are in distant locations that require travelling and when they receive no remuneration for WIL placement.

Service providers who implemented WIL also have resource challenges. Davies and Shirley (2007) indicate that managing students on WIL programmes, giving them feedback, allocating space for students to be placed, and the pressure of supervising students within their busy schedules are difficult. Jackson et al. (2015), and Erdem and Toklu (2016) explain that some organisations experience challenges in supervising and mentoring students due to their workloads and capacities. The Department of Industry (2014) in Australia maintains that it is one of the reasons why small organisations are reluctant to participate in WIL. The two common challenges that employers participating in WIL face are insufficient resources within their organisations and administration time (Department of Industry, 2014; Atkinson, Misko \& Stanwick, 2015). Atkinson and colleagues (2015) add a lack of clarity in objectives and outcomes as another concern for organisations. The Department of Industry (2014) in Australia lists other concerns at some organisations to be the lack of information available on WIL, terminology and language issues, management apathy toward WIL, budget concerns and managing the quality of the WIL experience. Billot and Choy (2013) mention that students encounter unpleasant and unhelpful experiences during WIL, indicating that these challenges may impact the quality of students' learning experience.

Two recurring challenges experienced by academic institutions are the costs associated with WIL and the increase in workload for academics (Patrick et al., 2008; Bates, 2011; Jackson et al., 2015; Clark et al., 2016). Smith (2012) indicates that WIL is relatively expensive teaching and learning methodology compared to standard classroom lectures and tutorials. Patrick and colleagues(2008) found that university management does not understand the amount of work involved in WIL and the specific skills required by academic and administrative staff. Student placement, monitoring, support and assessment, correspondence and associated administrative duties, database management, managing WIL contracts, and placement counselling add a great deal to workloads (Brown, 2010; Bates, 2011). Bates (2011) also found the WIL workload to have a direct impact on the promotion opportunities and research excellence of academics.

Another fundamental challenge for academics is to successfully embed WIL as pedagogy in the curriculum (McLennan \& Keating, 2008; Brown, 2010). Learning must include graduate attributes and employability skills, and work experiences should be integrated into the curriculum (Abeysekera, 2006; McLennan \& 
Keating, 2008; Brown, 2010). Abeysekera (2006) mentions that some service providers found students to be ill-prepared, less trained and less motivated to work and learn. Jackson (2014) and Brown (2010) reported that the assessment of WIL in the workplace is complex since it is difficult to measure employability skills. Brown (2010) indicates a need for consistency of assessment and clarity of expectations of all parties. McLennan and Keating (2008) also mention that the skills and experiences of academic staff are not always suitable for WIL programmes and that their skills lag behind industry standards.

Maintaining and fostering partnerships between stakeholders plays an important role in designing and implementing WIL (McLennan \& Keating, 2008; Rook, 2017). Academics have identified finding appropriate placements for a growing number of students to be a challenge, especially in health science education (Burns \& Grove, 2008; Bates, 2011), and establishing formal agreements with service providers are logistically difficult (Brown, 2010).

Although a considerable body of literature on the challenges of WIL is available internationally, information on South Africa, especially WIL in the pharmacy profession, is limited. Since patientorientated services have become the preferred mode of practice in pharmacy education in South Africa, pharmacy students are expected to be exposed to various professional practices to obtain the necessary skills and competencies they need for a rapidly changing health care environment (SAPC, 2017). In this article, the authors report on the views of the heads of pharmacy schools in South Africa about challenges experienced with WIL as articulated in the GPES. Based on the findings, recommendations are made on how to improve schools of pharmacy's compliance with the GPES concerning WIL.

\section{Method}

Schools of pharmacy heads at higher education institutions accredited by the SAPC as service providers for the BPharm programme $(n=9)$ were invited to participate in the study. Informed consent was obtained from the heads who agreed to participate in the study $(n=4)$. The principal investigator conducted semi-structured interviews with these heads, focusing on what challenges are experienced by students, HEls and service providers regarding WIL implementation. Semi-structured interviews were chosen so that the interviewees could have some degree of freedom to explain their views on the challenges of WIL and to enable certain responses to be questioned in greater depth.

There are mismatched expectations and gaps in what professional bodies expect from HEls and the WIL experiences the industry can deliver for students (Peach, Larkin \& Ruinard, 2012; SAPC, 2017). A thorough literature review was done to identify the challenges experienced globally with the implementation of WIL (McLennan \& Keating, 2008; Patrick et al., 2008; Spowart, 2012; Edwards et al., 2015). The following open-ended questions based on the literature research were included as part of the semi-structured interview:

Challenges - 'What, in your opinion, are the challenges of WIL at your institution?'

Under challenges, important subthemes in the literature were identified as:

Resources - 'To what extent did you need additional resources with the implementation of WIL?'

Infrastructure - 'How would you describe the sufficiency of your facilities for education and training to prepare students for workplace learning?'

Service providers - 'To what extent do you have a sufficient number of service provider contracts to accommodate all your students at the same time?'

The following close-ended questions were asked to create contexts for the challenges experienced by schools of pharmacy:

'How many students are enrolled in the BPharm programme in the different year groups?'

"When did your school start with WIL?"

'Did the school have to adjust their current programme to accommodate the new GPES on WIL promulgated in 2014, was their staff component affected by it, and who is responsible for supervision at the workplace site?'

The recorded interviews were transcribed and captured in Microsoft Word format by an independent transcriber who signed a confidentiality agreement. Upon receiving the transcribed interviews, the researcher listened to the interviews again and checked the transcriptions for correctness. To ensure the validity of the transcriptions, transcribed data were forwarded to the heads of schools to confirm that the transcribed data were a true reflection of their interview. Thereafter, the researcher applied deductive content analysis to identify, analyse and report recurring categories and subcategories relevant to the main point of discussion, which are the theme and subthemes in this study. Deductive content analysis is followed once: 
'the structure of analysis is operationalized on the basis of previous knowledge and the purpose of the study is theory testing' (Kyngäs \& VanHanen, 1999).

A deductive approach moves from general to specific based on a model or a theory (Burns \& Grove, 2008). The researcher copied data from each transcript into a Microsoft Excel spreadsheet to group similar categories and subcategories. The categories and subcategories identified were validated by one of the study's co-authors.

\section{Ethics approval}

The study was reviewed and approved by the ethics committees of the University of the Free State (HSREC 36/2016) and the North-West University (NWU-00366-15A1).

\section{Results}

Four of the nine heads of pharmacy schools in South Africa responded to the invitation to participate in the semistructured interview (44\% response rate). According to Burmeister and Aitken (2010), in qualitative research, neither a large nor a small sample size guarantees that data saturation has been reached but rather the richness of the data obtained and whether an appropriate research design was employed to enable the researcher to answer the research question.

In response to the history of WIL, interviewees indicated that their schools had started with WIL (formerly known to them as experiential learning) a few years ago. School A started WIL in 1990, School D in 1996, School B in 2003 and School C in 2013. Before the implementation of the GPES for WIL in 2014 (South Africa, 2014), there were no formal requirements for WIL implementation in South Africa pharmacy curricula.

School $C$ had the smallest number of students in the different year groups and in total, while School A had the largest number of students in the different year groups and in total. The student numbers of the four participating schools are presented in Table I.

Table I: Pharmacy student numbers per year level of each participating institution

\begin{tabular}{ccccc}
\hline Year level & \multicolumn{4}{c}{ Pharmacy student numbers } \\
& School A & School B & School C & School D \\
\hline 1 & 201 & 159 & 84 & 208 \\
2 & 220 & 145 & 104 & 156 \\
3 & 220 & 112 & 53 & 136 \\
4 & 269 & 94 & 80 & 132 \\
\hline Total & $\mathbf{9 1 0}$ & $\mathbf{5 1 0}$ & $\mathbf{3 2 1}$ & $\mathbf{6 3 2}$ \\
\hline
\end{tabular}

Schools B and D used pharmacists and other health care professionals to supervise students at the practice sites, and School B also used members of the community to assist with supervision. School A only used pharmacists, and School C used a combination of pharmacy lecturers from the institution, pharmacy managers and professional nurses.

Figure 1 presents the data network created from the analysis of the interview data. One main topic and subsidiary topics discussed during the interviews were used as themes and subthemes from which the data were categorised.

The participants identified several challenges with the implementation and introduction of the GPES of WIL. Under the theme of challenges, the following points were given for discussion: resources, infrastructure and service providers (subthemes).

\section{Resources (Subtheme A)}

Participants in this study described WIL as resourceintensive. Under this subtheme, the following two categories were identified: human resources with the subcategories WIL programme curriculum and student numbers, and financial resources with the subcategory budget constraints.

\section{Category A1: Human resources}

Schools A, B and C identified human resources as a challenge. School A reported that their school's human resource component is too small to accommodate the additional workload associated with implementing the WIL programme. School C explained their concerns about the impact that the new GPES requirements for WIL would have on their current teaching, learning and research burdens if no additional personnel are allocated to schools. Spending more time organising and managing WIL may be detrimental to their careers and negatively impact their performance and promotion in HEls. Some of their comments were:

School A: 'Personnel component are too small and we do not have clinical preceptors.'

School B: 'You need an extra administrative person to organise WIL.'

School C: 'With all the supervision and planning - we needed more staff members and we are only five staff members and we are supposed to teach from first to fourth year and do post-graduation work and we also need to do research - it is time-consuming.'

School D: 'You need an extra administrative person to arrange everything and we had to employ more staff.' 


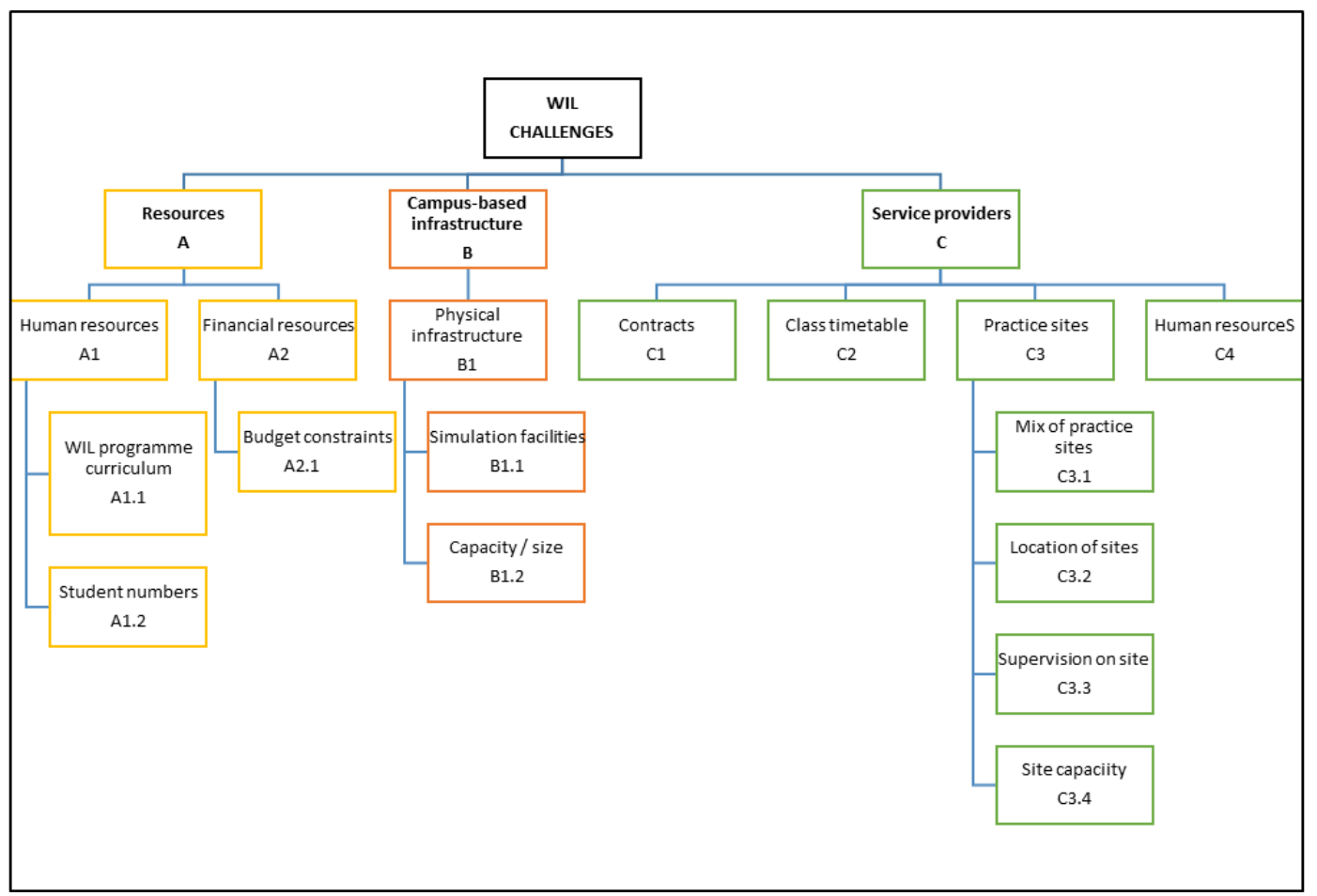

Figure 1: Data network from the semi-structured interviews

\section{Subcategory A1.1: WIL programme curriculum}

Schools A and B indicated that incorporating the WIL programme with the curriculum was a challenge. School A mentioned that the WIL programme was problematic because graduates need to be exposed to a mix of practice facilities in the public and private sector, which they could not necessarily accommodate. School B indicated that they find it difficult to formulate outcomes for certain WIL activities and that the assessment of professional practice experiences is difficult at times.

School A: 'The development of the WIL professional practice programme is very problematic as we need to accommodate three sectors, namely the pharmaceutical industry, community pharmacies, public sector, then we do not even talk about the Regulatory Council.'

School B: 'How to assess professional practice experiences? The assessment methods are sometimes tricky and to write the outcomes.'

\section{Subcategory A1.2: Student numbers}

School A, C and D indicated that student numbers are a challenge to the practical feasibility of WIL (See Table I). The large student numbers present a challenge to schools of pharmacy in their attempts to create similar experiences while accommodating all students in a restricted timetable and with a lack of practice facilities. The phrase the student numbers at our institution used by the participant from School A (student numbers $=910$ ) indicates that School $\mathrm{A}$ experienced greater difficulties in this respect than the other schools of pharmacy that participated in this study.

\section{Category A2: Financial resources}

The heads of the schools of pharmacy in this study agreed that additional financial resources are needed to implement WIL in pharmacy curricula.

\section{Subcategory A2.1: Budget constraints}

The sustainability of industrial site visits was questioned for one critical aspect: the large portion of the budget allocated to pharmaceutical industry visits. Schools A, B and D, identified transport costs as their main concern, and the largest part of their budgets was allocated to transport expenses. Such high transport costs are mainly a result of the great distances students often have to travel between the educational institutions and professional sites in the pharmaceutical industry. In some instances, students need to travel $150 \mathrm{~km}$ to the nearest site for periods of up to four weeks. However, access to clinics and hospitals appeared not to be a major issue from a financial viewpoint. 
School B: 'We definitely need additional resources - the budget is a challenge and in terms of the other health care sectors, the budget is not such a concern as we are surrounded by primary health care clinics and the hospitals are not too far.'

School C: 'We need additional resources for transport as we have large student numbers and practice sites in the public sector are far from the university - there is a lot of money needed for transport to get students to the different sites.'

\section{Campus-based infrastructure (Subtheme B)}

The following category and subcategories were identified under infrastructure:

\section{Category B1: Physical infrastructure}

Schools $C$ and $D$ described their facilities as sufficient, while Schools A and B indicated their need for additional infrastructure. Shortcomings in infrastructure result in the repetition of practicums, in some instances up to four times a week, which placed additional strain on staff. Some heads of schools indicated a need for additional infrastructure like space for students to reflect after WPL exposure. One participant mentioned that competition for space on their university campus is high.

School B: 'We do have a reasonably high infrastructure shortage on all levels - such as case study laboratories and space to do reflections - reflection is just as important as the preparation.'

School C: 'It [infrastructure] is good - I say good in the basics.'

\section{Subcategory B1.1: Simulation facilities}

Schools C and D indicated their need for additional simulation facilities to shorten the duration of WPL, especially the industrial experience, to limit costs.

School C: 'We would wish for simulation laboratories to simulate what is happening in the industry and if we have simulation it would imply that we can send our students maybe for one or two days (and not four weeks) to the industry.'

\section{Subcategory B1.2: Capacity/size}

School A had a capacity problem as their on-campus facilities were too small to equip all the students with the skills that the workplace required. As a result, practicums had to be repeated to accommodate large student numbers (cf. Table I), which implied greater staff workloads.
School A: 'Our facilities are sufficient, but the capacity of the facilities is too small - so it means practicums must be repeated that cause an additional burden on lecturers'.

\section{Service providers (Subtheme C)}

The results under Theme $\mathrm{C}$, service providers, are given below:

\section{Category C1: Contracts}

All the participants indicated that they had service provider contracts in place in some cases. School B indicated that they had 50 contracts in place while School $D$ reported the long time it took their institution to sign a memorandum of understanding with the Department of Health. School $C$ indicated that it is difficult to secure service provider contracts in all the sectors. Only some of the participant institutions have contracts with community pharmacies and private hospitals, and contracts with the pharmaceutical industry are problematic. The head of School C mentioned that their service provider contracts are managed by university management to incorporate all the health professions represented.

School A: 'We currently have two WIL contracts - we work on a third one and we do have contracts with community pharmacies, and we are in the process to obtain contracts with the large community pharmacy groups.'

School B: 'We do have about 50 service providers - we are lucky and the service providers [partners] are willing to be involved and our alumni also wants to be involved with the university.'

School C: 'It is difficult to get contracts in each sector and contracts with hospitals and the clinics are done by the university management as it is not only pharmacy students - we have medical, nursing and optometry students in practice and for the retail pharmacy, you really do not need the contracts per se, unless we have a contract with a corporation or a pharmaceutical group - at this stage we do not have contracts with community pharmacies although it is something we can do and the one that is very difficult, probably with all pharmacy schools, is to get a contract with the pharmaceutical industry. The reason is by nature of their business and the way they operate.'

School D: 'We have an official memorandum of understanding with the National Department of Health -it took us four years to write it and get it approved and with the private hospital sector we have a verbal agreement.' 


\section{Category C2: Class timetable}

The head of School B reported that their institution's class timetable is congested, which makes it difficult to schedule WIL. It is not always possible for the service providers or partners at the practice facilities to adapt to the university's timetable.

School B: 'The campus schedule makes it difficult to do WIL, professional practice, effectively and the campus schedule determines what you can do in professional practice - the partners [service providers] cannot always adapt to our schedule.'

\section{Category C3: Practice sites}

All participants reported that choosing, managing and using the practice sites are challenges, highlighting the aspects below.

\section{Subcategory C3.1: Mix of practice sites}

Schools C and D indicated that they experience difficulties finding an industrial placement for their students because of the increased competition between schools of pharmacy for placements and limited sites for the pharmaceutical industry. Pharmaceutical industries are bound to a timetable for quality assurance and internal and external audits. Access to the industry is restricted during these periods, and students cannot be placed. School C indicated that students must find a placement in the retail community pharmacy sector by themselves and that they only receive assistance with placements when they experience difficulties in finding one. School D reported that they find it difficult to expose students to a mix of practice facilities, and in some instances, the availability of sites is limited.

School C: 'The students need to find placement in the retail pharmacy on their own - we help them if they experience problems and competing with other pharmacy schools for industrial placement is becoming an issue - the pharmaceutical industry has their own programmes maybe an upcoming audit and then that specific year they cannot accommodate anybody pharmaceutical companies merge or close down.'

School D: 'I don't think we have sufficient sites - it would be great if we could make all our students go work in a manufacturing plant.'

\section{Subcategory C3.2: Location of sites}

Schools B and D found the distance between practice sites and the area of the school to be a common difficulty. School B expressed their concerns about the civil instabilities that sometimes occur at sites that hamper the placement schedule. The rigid timetable means that the placement cannot be repeated. School D was concerned about the distance between the academic institution and the nearest industry $(150 \mathrm{~km})$.

School B: '[...] location of your community and the violence in certain places are sometimes problematicwe are concerned about it and sometimes the students cannot go where they must go for the day and the students are away for long periods as it includes transport.'

School D: 'Location of higher education institution and our closest industry is $150 \mathrm{~km}$ away.'

\section{Subcategory C3.3: Supervision on site}

Schools $C$ and $D$ reported limited supervision at sites as problematic because sites are commonly understaffed. School D reported that supervision at public clinics is constantly a problem and that some clinics were even closed when students arrived without prior notice.

School C: 'The pharmaceutical industry does not have the human resources to teach our students and sites are not prepared to help us, or they're short staffed, or sometimes they are even closed.'

School D: 'Sufficient supervision [...] supervision is a constant problem - these local clinics are sometimes not even open.'

\section{Subcategory C3.4: Site capacity}

School $\mathrm{C}$ indicated that the number of students that can be accommodated per site is limited, even though School C's student numbers are the lowest of the participating schools (minimum $=53$ and maximum $=$ 104, per year level). School D indicated that the Medicines Control Council (MCC) could only accommodate five students at that time while the pharmaceutical industry could accommodate three students.

School D: 'You go to MCC, they say they can only take five students, then you go to this company, three students.'

\section{Category C4: Human resources}

School D reported that the human resources at the pharmaceutical industries are limited and that they cannot engage in training and mentoring students.

School D: 'Pharmaceutical industries do not have the human resource to teach us.' 


\section{Discussion}

To be registered with the SAPC as providers of the pharmacy degree, schools of pharmacy need to comply with the GPES (SAPC, 2017a) and meet the requirements during evaluations every four to five years by a board of experts in the field of pharmacy appointed by the SAPC. In 2014, the GPES (South Africa, 2014) was published with the first set of criteria for WIL, and schools of pharmacy had to adapt to this new set of standards. The criteria for WIL set by the SAPC refer to workplace or professional practice experiences for schools of pharmacy. The purpose of this research was to investigate the challenges experienced by schools of pharmacy in implementing the new GPES on WIL and to provide recommendations on the implementation of WIL.

\section{Challenges}

The challenges identified by the participating South African schools of pharmacy concur with the findings found in the literature (Bates, 2005; Bates, 2011; Yorke \& Vidovich, 2014; Xu, 2015). The main challenges identified in this study were resources, infrastructure and service providers.

\section{Resources}

The implementation of WIL places an additional burden on human resources (Bates, 2011), with the need for extra administrative personnel as the logistics and support needed increases significantly once a WIL programme is implemented. If this additional work had to be handled by academics, it would have a negative impact on staff's career prospects. School of pharmacy heads were especially concerned that WIL commitments leave little time for research and scholarships, as confirmed by Bates (2011) and Patrick and colleagues (2008).

Developing a WIL programme for the South African context is problematic in the sense that the GPES prescribes WIL training in a mix of practice facilities (hospital pharmacies in both the public and private sector, community pharmacies, primary health care clinics, the pharmaceutical industry and regulatory authorities). However, access to these resources is difficult due to reasons that may be particular to the South African context; for example, placement at manufacturing plants is not common practice in South African pharmacy training. Also, access to WIL training sites is limited due to the number of students that need placements (Patrick et al., 2008; Xu, 2015), or access can be blocked due to civil unrest and transport and accommodation problems.
The financial burden of WIL training was mentioned as a challenge for all the role players. McLennan and Keating (2008) list the 'type of WIL program, maintaining partnership with many employers, sourcing WIL opportunities, developing and evaluating curriculum for WIL, and supporting a body of students who are geographically dispersed' as items impacting on financial resources. In South Africa, the impact of transport costs and additional staff costs on already stretched budgets is very real. Some institutions do carry the costs for transportation to ensure placement for students in all the different pharmaceutical sectors, however Bates (2005) and Davies and Shirley (2007) report that students, and not necessarily the institutions, are responsible for extra expenses like travel and accommodation costs. The South African pharmaceutical industry is concentrated in the main cities, while public health facilities are situated in formal and informal settings. These placements are rarely in the same region as the university and require travel. This raises the question of access, with many students experiencing financial challenges, limiting their ability to pay for these extra expenses. These costs are also elevated by the distance between the different practice sites, which then raises questions regarding the sustainability of WIL.

\section{Infrastructure}

HEls, in general, are confronted with 'ageing and expanding facilities' that require upgrades and expansion (Burch, 2014) to accommodate future classes. They also lack affordable spaces, technology and laboratories (Hayden et al., 2014). Simulation facilities are known to be costly, and running as well as maintaining, repairing and replacing these facilities require ongoing funding (Burch, 2014). In the South African context, the size and capacity of on-campus facilities are insufficient to accommodate large student numbers in the schools of pharmacy, not only for traditional teaching and learning but also for WIL related activities such as planning and reflections sessions.

\section{Service providers}

Weisz and Smith (2005) explain the importance of establishing a contract between the university, workplace, and students that outlines the requirements for all parties to provide a clear guide on the respective roles and responsibilities (Weisz \& Smith, 2005). Although contracts with service providers were mostly in place, these contracts do not necessarily extend to the smaller retail pharmacies. Smaller WIL programmes may not see the necessity of a formal contract, but it is desirable to have contracts in place, 
especially for larger programmes, in order to facilitate sustainability (Higher Education Quality Council of Ontario, 2016). As most students will find employment either in hospitals or community pharmacies, exposure to these placements are crucial (Australian Pharmacy Council, 2012; Accreditation Council for Pharmacy Education, 2015). Additional placements in other settings like general practice, residential care facilities, primary care, community nursing, the pharmaceutical industry, and policy and regulatory settings should be encouraged (Australian Pharmacy Council, 2012; Accreditation Council for Pharmacy Education, 2015) not only for experience but also for accommodating large student numbers. Findings from this study indicated exposure to community pharmacies, public health care clinics and some exposure to the pharmaceutical industry practice sites, while the literature indicated only two settings: community and hospital pharmacies.

Aligning campus timetables with service provider needs seems to be challenging for WIL planning as the university timeframes differ from the commercial realities (Atkinson, 2015), and both parties have to negotiate acceptable timeframes for WIL to be sustainable.

In South Africa, the number of available and accredited WIL service providers is less than the number of students who need to participate in WIL training, leading to competition between schools of pharmacy, as explained by McLennan and Keating (2008), especially where regions are closer together. It is problematic when WIL placements are being sought at the same time by all local universities and in the same parts of a particular sector (Reeve \& Gallacher, 2005; Health Workforce Australia, 2011; Peach et al., 2012; Manzar-Abbas \& Lu, 2013).

Student supervision at the WIL sites is a continuous challenge for reasons such as the number of placements and distance. Supervision of WIL is essential in assessing student outcomes (Cooper \& Orrell, 2010), and staff at the service providers are required to provide additional supervision to that provided by the university lecturer. However, many of these sites are short-staffed and even sometimes closed, which limits the availability of supervised WIL time for the students. This impacts the class timetable directly, as opportunities to repeat a WIL session are limited. It is still compulsory for students to complete the specified number of WIL hours during their training, and fewer WIL sessions create problems for these students. The effective use of the WIL hours is crucial, and the study highlights the need to focus on clearly defined outcomes to ensure that the time students spend engaging with WIL activities is effectively used and that students are adequately prepared before their WIL placement (Xu, 2015).

This study also highlighted that site capacity is a challenge as the number of students that can be accommodated at a specific site is limited. It implies that more sites are required, and more service providers in the different sectors need to be willing to participate in order to accommodate larger student numbers and the need for placements, as suggested by the Department of Industry in Australia (2014), Xu (2015) and Atkinson and colleagues (2015). The lack of adequate placements maybe because of the time and workload associated with the supervision of students (Department of Industry, 2014; Atkinson et al., 2015; $\mathrm{Xu}, 2015)$.

\section{Recommendations}

To address the challenges identified in this study, the following recommendations for resources, infrastructure and service providers are proposed.

\section{Resources}

Decision-makers in HEls should consider following a systematic approach to sourcing to provide a diverse WIL curriculum in collaboration with government, service providers and professional bodies.

An investigation should be launched on the different WIL approaches, both in the university context and workplace setting to suit each individual university and its respective clinical sites and to increase curriculum flexibility. Universities should consider faculty (academic) and institutional capacity to implement WIL as a teaching and learning approach, as well as institutional support structures to assist academics and faculties with the development of WIL outcomes and their implementation.

It is recommended that academics involved in WIL engage with senior management about their WIL workloads to incorporate them into their promotion pathways. The administrative burden of WIL on academics can be relieved by using a centralised system for placing students at different practice sites for the faculty or the school or by using an expert to manage an institution-wide database.

More financial resources should be allocated to all activities associated with a structured WIL programme. It is recommended that schools of pharmacy in South Africa consider simulation, online or virtual technologies on campuses and visits and demonstrations by experts from the pharmaceutical industry. This would minimise the financial and temporal constraints associated with pharmaceutical industry visits since these initiatives will minimise the 
need for students to visit the pharmaceutical industry in person.

\section{Campus-based infrastructure}

Some schools of pharmacy in South Africa experience difficulty obtaining sufficient infrastructure due to competition between the different schools, while others need to expand their current facilities to accommodate large student numbers. It is recommended that university management teams and government engage in talks about the allocation of funds for WIL infrastructure. Universities should seek external funding to address the growing need for service providers. They should also investigate possibilities of using information technology to address some of the challenges regarding large student numbers, such as simulation laboratories. According to a study by Hayden and colleagues (2014), strong evidence supports that simulation can effectively replace traditional clinical hours by up to $50 \%$ without compromising graduate outcomes.

\section{Service providers}

A WIL programme's sustainability requires commitment from universities and the industry. A sustainable WIL programme depends on a sufficient number of service providers from different sectors of the pharmacy industry, preceptors who are willing to assist and mentor students, and a flexible university timetable that enables students to participate in WIL.

It is recommended that formal contracts (memoranda of agreement (MOAs) or memoranda of understanding (MOUs)) be signed between all role players to ensure the sustainability and high quality of WIL, as well as to ensure their commitment. It is relevant for large and small WIL programmes.

Although the class timetable remains a challenge, it is recommended that universities consider greater flexibility across the year with respect to the placement. Further collaboration between universities and service providers is required to provide a suitable time for WIL activities. Universities and WIL programme coordinators in the different disciplines should collaborate when planning the class timetable. A co-operative education system can also be considered for periods during which students are offcampus, as is done with WIL in Canada (Business-Higher Education Roundtable, 2015). A co-operative education system can be extended to student holidays so that students can work where they stay, which could address some of the WIL challenges around transport and accommodation.

\section{Limitations of the study}

Disruptions in the higher education environment in South Africa, namely the \#FeesMustFall movement, resulted in four of the nine heads of schools of pharmacy not replying to an invitation to participate in the study, while another agreed, but the researcher was subsequently unable to contact the participant after several attempts. The low response rate of the school of pharmacy heads in South Africa (four of the nine registered schools) prevented the researcher from obtaining the viewpoints of all the schools of pharmacy.

\section{Recommendations for future studies}

To increase the response rate of the study, goodwill permission could be obtained from the SAPC to interview the pharmacy school heads concurrently with the SAPC heads of school meetings, where attendance is compulsory. It might enable the researcher to reach more participants. Further investigation of WIL-related issues should be conducted, and all the stakeholders should be invited to give input. This feedback can also be taken into account when the GPES is revised.

\section{Conclusion}

This study investigated the implementation of WIL in South African schools of pharmacy to determine the current situation and identify challenges. While aspects like financial constraints, human resources, site capacity, supervision at sites and large classes continue to challenge schools of pharmacy in South Africa, there is evidence that progress is being made with the implementation of WIL according to the GPES. The consistency of these results with other evidence in the literature supports the fact that the abovementioned factors remain a challenge for South African schools of pharmacy and other training institutions using WIL.

\section{Declaration of interest}

The authors declare that there is no conflict of interest.

\section{References}

Abeysekera, I., (2006). “Issues Relating to Designing a WorkIntegrated Learning Program in an Undergraduate

Accounting Degree Program and Its Implications for the Curriculum." Asia-Pacific Journal of Cooperative Education, 7, 7-15.

https://ro.uow.edu.au/cgi/viewcontent.cgi?article=1579\&co ntext=commpapers 
Accreditation Council for Pharmacy Education. (2015). Accreditation and Key Elements for the Professional Program in Pharmacy Leading to a Doctor of Pharmacy Degree ("Standards 2016"). Chicago, ILL: Accreditation Council for Pharmacy Education. https://www.acpeaccredit.org/pdf/Standards2016FINAL.pdf

Atkinson, G., Misko, J., \& Stanwick, J. (2015). Work Integrated Learning in STEM Disciplines: The Employer Perspective. Adelaide: National Centre for Vocational Education Research.

https://www.voced.edu.au/content/ngv\%3A69544

Australian Pharmacy Council. (2012). Accreditation standards for pharmacy programs in Australia and New Zealand.

https://www.pharmacycouncil.org.au/resources/pharmacyprogram-standards/

Bates, L. (2005). Building a Bridge between university and employment: Work integrated learning: Research Brief 2005/08. Brisbane: Queensland Parliamentary Library. http://www.parliament.qld.gov.au/documents/explore/rese archpublications/researchbriefs/2005/200508.pdf

Bates, M. (2011). "Work-Integrated Learning Workloads: The Realities and Responsibilities." Asia-Pacific Journal of Cooperative Education, 12(2), 111-124

Billot, S., \& Choy, S. (2013). "Learning Through Work: Emerging Perspectives and New Challenges." Journal of Workplace Learning, 25(4), 264-276.

https://doi.org/10.1108/13665621311316447

Brown, N. (2010). "WIL[ling] to Share: An Institutional Conversation to Guide Policy and Practice in WorkIntegrated Learning." Higher Education Research and Development, 29(5), 507-518.

https://doi.org/10.1080/07294360.2010.502219

Burch, V. (2014). "Does Simulation-Based Training Have a Future in Africa?" African Journal of Health Professions Education, 6(2), 117-118.

https://doi.org/10.7196/AJHPE.534

Burmeister, E., \& Aitken, L.M. (2010). "Sample Size: How Many Is Enough?" Australian Critical Care, 25(4), 271-274. http://www.australiancriticalcare.com/article/S10367314(12)00084-7/pdf

Burns, N., \& Grove, S.K. (2008). The Practice of Nursing Research: Conduct, Critique \& Utilization. Saunders: Elsevier, St Louis

Business Higher Education Roundtable. (2015). Taking the Pulse of Work-Integrated Learning in Canada. Academica Group.

https://www.queensu.ca/experientiallearninghub/faculty/re ports

Calway, B., \& Murphy, G. (2007). "The Educational Imperatives for a Work-Integrated Learning Philosophy." Journal of Cooperative Education and Internships, 41(2), 1222

Campbell, M., \& Zegwaard, K.E. (2012). "Ethical

Considerations and Values Development in Work-Integrated Learning Programs." In Proceedings of the Australian Collaborative Education Network (ACEN) National
Conference. Geelong: Deakin University.

https://www.academia.edu/2878316/Ethical_consideration s_and_values_development_in_work_integrated_learning_ programs

Clark, L., Rowe, A., Cantori, A., Bilgin, A., \& Mukuria, V. (2016). "The Power Dynamics and Politics of Survey Design: Measuring Workload Associated with Teaching,

Administering and Supporting Work-Integrated Learning Courses." Studies in Higher Education, 41(6), 1055-1073. https://doi.org/10.1080/03075079.2014.966071

Cooper, L., Orrell, J., \& Bowden, M. (2010). Work Integrated Learning: A Guide to Effective Practice. Routledge: New York. https://doi.org/10.4324/9780203854501

Davies, I.T., \& Shirley, M.J. (2007). "Internationalising WorkIntegrated Learning for Law Students." In Proceedings of the 15th World Conference on Cooperative Education (WACE). Singapore: WACE

Department of Industry. (2014). Engaging Employers in Work Integrated Learning: Current State and Future Priorities. Victoria, Australia: PhillipsKPA.

https://www.phillipskpa.com.au/case-studies/highereducation/engaging-employers-in-work-integrated-learningcurrent-state-and-future-priorities

Dwesini, N.F. (2017). “Exploring Key Challenges Encountered by Hospitality Management Students Participating in a Work-Integrated Learning (WIL) Programme in South Africa." African Journal of Hospitality, Tourism and Leisure, 6(2), 1-10.

http://www.ajhtl.com/uploads/7/1/6/3/7163688/article_10 _vol_6_2__2017.pdf

Edwards, D., Perkins, K., Pearce, J., \& Hong, J. (2015). Work Integrated Learning in STEM in Australian Universities: Final Report Submitted to the Office of the Chief Scientist. Australian Council for Educational Research (ACER). https://research.acer.edu.au/cgi/viewcontent.cgi?article $=10$ 46\&context=higher_education

Erdem, M.B., \& Toklu, M.C. (2016). “Standardization of Cooperative Education Processes via Management Information Systems." Journal of Quality in Higher education, 3(2), 65-68.

https://www.tojqih.net/journals/tojqih/articles/v03i02/v03i 02-07.pdf

Hayden, J.K., Smiley, R.A., Alexander, M., Kardond-Edgren, S., \& Jeffries, P.R. (2014). "The NCSBN National Simulation Study: A Longitudinal, Randomized, Controlled Study Replacing Clinical Hours with Simulation in Prelicensure Nursing Education." Journal of Nursing Regulation, 5(2), 166. https://doi.org/10.1016/S2155-8256(15)30062-4

Health Workforce Australia. (2011). Mapping Clinical Placements: Capturing Opportunities For Growth. Adelaide: Health Workforce

Higher Education Quality Council of Ontario. (2016). A Practical Guide for Work-Integrated Learning: Effective Practices to Enhance the Educational Quality of Structured Work Experiences Offered Through Colleges and Universities. Toronto: Queen's Printer for Ontario. https://www.vu.edu.au/sites/default/files/CCLT/pdfs/heqco -practical-guide-wil.pdf 
Jackson, D. (2013). "The Contribution of Work-Integrated Learning to Undergraduate Employability Skill Outcomes." Asia-Pacific Journal of Cooperative Education, 14(2), 99-115

Jackson, D. (2014). "Employability Skill Development in Work-Integrated Learning: Barrier And Best Practice." Studies in Higher Education, 40(2), 350-367. https://doi.org/10.1080/03075079.2013.842221

Jackson, D., Ferns, S., Rowbottom, D., \& McLaren, D. (2015). Working Together to Achieve Better Work-Integrated Learning Outcome: Improving Productivity Through Better Employer Involvement. Perth: Edith Cowan University. http://acen.edu.au/wp-content/uploads/2016/06/Workingtogether-to-achieve-better-WIL-outcomes.pdf

Kyngäs, H., \& VanHanen, L. (1999). “Content analysis" (Finnish). Hoitotiede, 11, 3-12

Manzar-Abbas, S., \& Lu, L. (2013). “Collaboration Problems During Practicum in Pre-Service Teacher Education in Pakistan." Academic Research International, 4(3), 379-393

McLennan, B., \& Keating, S. (2008). “Work-Integrated Learning (WIL) in Australian Universities: The Challenges of Mainstreaming WIL." In ALTC NAGCAS National Symposium. Melbourne.

http://citeseerx.ist.psu.edu/viewdoc/download;jsessionid=C 33E72DB3DA417BFDBEA2BA90CC23685?doi=10.1.1.530.44 $43 \&$ rep $=$ rep $1 \&$ type $=$ pdf

Patrick, C., Peach, D., Pocknee, C., Webb, F., Fletcher, M., \& Pretto, G. (2008). The WIL Report-Work Integrated Learning: A National Scoping Study. Final Report to the Australian Learning and Teaching Council. Brisbane: Queensland University of Technology.

http://eprints.qut.edu.au/44065/1/WIL-Report-grantsproject-jan09.pdf

Peach, D., Larkin, I., \& Ruinard, E. (2012). “High Risk, High Stake Relationships: Building Effective Industry-University Partnerships for Work Integrated Learning (WIL)." In Proceedings of the ACEN 2012 Conference. Brisbane: Queensland University of Technology.

http://acen.edu.au/wp-content/uploads/2015/09/ACEN2010-Proceedings.pdf?x99824

Pitout, B.R. (2009). "Transforming Work-Integrated Learning: Strengths, Shortcomings and Solutions." Journal for New Generation Sciences, 7(1), 176-202.

https://journals.co.za/doi/abs/10.10520/EJC83514

Reeve, F., \& Gallacher, J. (2005). “Employer-University 'Partnerships': A Key Problem for Work-Based Learning Programmes?" Journal of Education and Work, 18(2), 219233. https://doi.org/10.1080/13639080500085992

Rook, L. (2017). “Challenges Implementing Work-Integrated Learning in Human Resource Management University Courses." Asia-Pacific Journal of Cooperative Education, 18(3), 199-212.

https://files.eric.ed.gov/fulltext/EJ1156043.pdf

SAPC (South African Pharmacy Council). (2017). Good Pharmacy Education Standards Amended (Higher Education and Training).

https://www.pharmcouncil.co.za/media/default/documents /Good_Pharmacy_Education_Standards_(HET)_(2017).pdf
Smith, C. (2012). "Evaluating the Quality of Work-Integrated Learning Curricula: A Comprehensive Framework." Higher Education Research and Development, 31(2), 247-262. https://doi.org/10.1080/07294360.2011.558072

South Africa. (1994). Department of Health. Regulations Relating to the Minimum Requirements of the Curriculum for a Degree in Pharmacy. R.1528 of 9 September 1994. Pretoria: Government Printers

South Africa. (2014). Good Pharmacy Education Standards in Terms of Section 34 of the Pharmacy Act, Act 53 of 1974. Notice 153. Pretoria: Government Printers.

https://www.mm3admin.co.za/documents/docmanager/0C 43CA52-121E-4F58-B8F6-81F656F2FD17/00081072.pdf

Spowart, J. (2012). “Preparing Future-Fit Leaders: The Challenge of Work Integrated Learning in The Faculty of Management in a Comprehensive University: A Discussion Paper." Johannesburg: World Association for Cooperative Education (WACE).

http://www.waceinc.org/bahcesehir2012/cp/refereed/Sout hAfrica/Jane\%20Spowart\%20University\%20of\%20Johannes burg\%20(Discussion)\%20Preparing\%20future\%20fit\%20lead ers.pdf

Thorne, P. (2010). Supporting, Assessing and Accrediting Workplace Learning. London: Cassell

Weisz, M., \& Smith, S. (2005). "Critical Changes for Successful Cooperative Education." In Higher Education in a Changing World: Research and Development In Higher Education: Proceedings of the $28^{\text {th }}$ HERDSA Annual Conference. Sydney.

https://conference.herdsa.org.au/2005/pdf/refereed/paper _289.pdf

$\mathrm{Xu}, \mathrm{J}$. (2015). Implementation of Workplace Learning in the Accountancy Schools of Australian Universities. Master of Business. Brisbane: Queensland University of Technology. https://eprints.qut.edu.au/84346/1/Jia_Xu_Thesis.pdf

Yorke, J., \& Vidovich, L. (2014). "Quality Policy and the Role of Assessment in Work-Integrated Learning." Asia-Pacific Journal of Cooperative Education [Special issue], 15(3), 223237 